\title{
DIREITOS HUMANOS E DEMOCRACIA: a razão existencial e a invenção e conservação dos Direitos Humanos \\ HUMAN RIGHTS AND DEMOCRACY: Existential Reason and the Invention and Conservation of Human Rights
}

\author{
Prof. Dr. Gustavo Barbosa de Mesquita Batista ${ }^{1}$ \\ Professor Adjunto do Departamento de Direito Público da UFPB \\ gustavobm.batista@gmail.com
}

SUMÁRIO: 1. Introdução; 2. Razão Existencial e Universalidade dos Direitos Humanos; 3. Vida Democrática e Direitos Humanos: os avanços num modelo social aberto; 4. A Conservação de Direitos Humanos como paradoxo democrático: a ideia de Constituição; 5. Considerações Finais.

RESUMO. O tema dos Direitos Humanos demanda uma discussão sobre racionalidade e democracia. Não é possível sustentar os Direitos Humanos sem o fundamento da existência e morte do sujeito. É esta razão existencial que nos permite intuir a universalidade dos Direitos Humanos. São as formas de existência plurais que determinam a diversidade dos sujeitos e das perspectivas de compreensão dos Direitos Humanos e é neste modelo comunicacional aberto e democrático que avançamos e criamos a oportunidade de reconhecimento de sujeitos e direitos. Entretanto, se por um lado, há uma função revolucionária e transformadora do mundo e da sociedade por parte dos Direitos Humanos, atualmente, surge, de forma igual, a necessidade de uma função conservadora das formas de existência por ele protegidas. Observa-se que, se pela democracia chegamos ao reconhecimento dos Direitos Humanos, ela também traz consigo riscos que sugerem uma posição contrarrevolucionária e de conservação de direitos contra maiorias tirânicas. 0 presente estudo constitui uma abordagem filosófica e política dos Direitos Humanos, construída a partir de argumentos de cunho existencialista e crítico da razão instrumental moderna.

Palavras-Chave: Direitos Humanos; Razão Existencial; Democracia.

ABSTRACT. The theme of Human Rights demands a discussion about rationality and democracy. It is not possible to sustain human rights without the foundation of the subject's existence and death. It is this existential reason that allows us to realize the universality of Human Rights. It is the plural forms of existence that defines the diversity of the subjects and the perspectives of understanding Human Rights and it is in this open and democratic communication model that we advance and create the opportunity of recognition of subjects and rights. However, while on

\footnotetext{
1 Professor Adjunto do Departamento de Direito Público da UFPB. Doutor em Teoria Dogmática do Direito pela UFPE (2011). Orientador de Mestrado e Doutorado dos Programas de Pós-Graduação em Ciências Jurídicas e de Políticas Públicas, Cidadania e Direitos Humanos da UFPB. Vice Coordenador do Programa de Pós-Graduação em Políticas Públicas, Cidadania e Direitos Humanos da UFPB.
} 
the one hand there is a revolutionary and transforming function of the world and society on the part of Human Rights, there is also a need today for a conservative function of the forms of existence protected by it. It is observed that if by democracy we settled to the recognition of Human Rights, it also brings with it risks that suggest a counterrevolutionary position and conservation of rights against tyrannical majorities. The present study constitutes a philosophical and political approach to Human Rights, built on arguments of an existentialist and critical view of modern instrumental reason.

KEYWORDS: Human Rights; Existential Ratio; Democracy.

\section{Introdução}

A ideia de que "todos os homens nascem iguais em direitos e dignidade" consagra uma perspectiva de Direitos Naturais e Universais para os Direitos Humanos, como se este reconhecimento fosse, diretamente, produto da humanidade do sujeito. Quem é este sujeito humano? Como compreendemos o seu papel sobre o mundo? Que pessoas são definidas como sujeitos neste mundo: todas ou apenas algumas? Rapidamente, descobrimos que não existe um "consenso universal" sobre quem é este sujeito, qual o seu papel sobre o mundo e como o reconhecimento dos Direitos Humanos é possível para todas as pessoas? Este mundo foi se construindo lentamente, é parte da razão ocidental, do símbolo da autonomia individual, da compreensão de uma sociedade de indivíduos e todas as implicações daí resultantes. Trata-se de um mundo em conflito com "outros mundos" e outras formas da razão não modernas ou Ocidentais, mas que persistem, inclusive, como linguagens e maneiras de expressar o pensamento e existência humana e de se comunicar.

Tomando nota do conflito, da existência de outros "mundos" e da diversificação e riqueza das linguagens, já não é possível compreender os Direitos Humanos como direitos naturalmente dados ou imanentes. Eles são produto da cultura e de lutas históricas que geram novas práticas comunicativas e de acesso ao reconhecimento de sujeitos e identidades. São o resultado dos valores existenciais que geraram e expressaram, de forma comunicativa e consensual, o seu reconhecimento em favor de pessoas ou grupos de pessoas. Definem o "outro espelhado em nós mesmos" pela história existencial de angústias, sentimentos e sofrimentos. 
Dificilmente as condições de linguagem, comunicação e reconhecibilidade são universais, mas nada impede que esta luta continue e se busque a consagração da "Universalidade dos Direitos Humanos". Dois problemas aqui se posicionam: um relativo a uma "visão hegemônica" de sociedade melhor e dos valores que nela merecem ser preservados como próprios da existência ou desenvolvimento da comunidade. Outro problema, subordinado ao primeiro, é que no próprio mundo dos Direitos Humanos, existe um intenso conflito com relação ao seu significado ou o projeto de sujeito e sociedade a ser alimentado por eles. Conforme os paradigmas em debate, acentuam-se determinadas perspectivas dos Direitos Humanos. Há uma perspectiva que consagra modelos de autonomias individuais comprometidas com uma cultura econômica liberal e concorrencial e um aparelho burocrático racional que promove as liberdades, limitando os poderes do Estado, sobretudo: os poderes fiscal e penal. E há outra perspectiva que consagra os aspectos da justiça distributiva e o papel do Estado na promoção da igualdade, voltando-se para o fortalecimento de organizações coletivas em busca de proteção social contra a desigualdade, demandando, dessa forma, uma atuação positiva do Estado como promotor de políticas sociais de igualdade.

Ambos os modelos determinam formas do Estado e da sociedade fundadas na razão instrumental moderna que são reveladores de uma disputa no Ocidente acerca do significado dos Direitos Humanos: direitos individuais que limitam os poderes do Estado ou direitos coletivos que protegem socialmente as pessoas contra os males da desigualdade, provocada pela concentração das riquezas sociais?

Isoladamente, estas perspectivas não conseguem dimensionar, por completo, o que se comunica pela expressão Direitos Humanos, pois exigem esforços de compreensão múltipla e aproximação. Quaisquer delas, também, são insuficientes para se comunicar com "outros mundos", em especial, o Oriente, sua cultura e as diversas religiões professadas, a fim de produzir novos consensos e ampliar os canais de reconhecibilidade dos Direitos Humanos. Decerto, liberdade, igualdade e fraternidade aspiram universalidade, mas possuem delimitações conceituais distintas, conforme modelos políticos e mundos culturais nos quais seus conceitos são maturados e colocados à prova. 
Há sempre o risco de uma articulação, imperialista e Ocidental dos Direitos Humanos, como projeto de potências do Ocidente, vinculadas a um ou outro significado destes Direitos e seus programas civilizatórios de pretensão global. Os processos de internacionalização das correntes Ocidentais dos Direitos Humanos sempre observaram tais dificuldades na promoção de uma comunicação intercultural e de compreensão de vários modelos e formas para se exercitar ou praticar, junto às várias comunidades humanas, estes Direitos. É necessário, portanto, tentar ultrapassar estas experiências civilizatórias a partir das perspectivas Ocidentais em disputa e produzir estratégias de aproximação aberta e comunicativa aos Direitos Humanos. Oportuno seria o aparecimento de diversas matizes de convivência e diálogo, aptas a gerarem o reconhecimento e o exercício destes direitos por parte de um número cada vez mais abrangente e diversificado de pessoas.

\section{Razão existencial e universalidade dos Direitos Humanos}

Decerto, os Direitos Humanos são uma “invenção Ocidental”, há neles um conjunto de normas e garantias reconhecidas, paulatinamente, em virtude de conflitos observados no desenvolvimento histórico do Ocidente. Valores presentes no cristianismo e no judaísmo alicerçam, fortemente, a Cultura Ocidental e são reconhecidos nas Declarações de Direitos, historicamente datadas no Ocidente desde a Magna Carta inglesa e da incessante busca de se impor limites ao Poder Real. Esta apreensão intuitiva a partir de uma "fonte metafísica" comum e religiosamente experienciada no Ocidente foi fundamental para a construção histórica de uma Declaração destes Direitos como atualmente a percebemos. A fundamentação metafísica e o recurso à Lei Natural para justificar a ordem política e a origem dos Direitos Civis e dos limites ao Poder Real, igualmente, influenciou sua compreensão como "direitos naturais" comuns a todos os homens, perceptível, por exemplo, em como declararam os protestantes dos Países Baixos por ocasião da turbulenta disputa religiosa na Europa: Deus criou os homens livres e, eles, não podem ser escravizados por pessoas que sobre eles não têm poder algum a não ser o que eles próprios concederam (SKINNER, 2006: p. 607).

0 fato é que isso deixou em segundo plano que, na realidade, houve um lento caminhar histórico que determinou mudanças na forma de pensar e de se 
comunicar, intersubjetivamente, propiciando o ambiente (ou mundo) em que os Direitos Humanos são reconhecidos. À medida que o tempo passava, aprendíamos socialmente, não apenas a reproduzir as velhas estruturas, mas igualmente a modificá-las para produzir novas experiências e avanços comunicativos e de linguagem. Este lento processo de domesticação dos costumes e de disciplina da mente, da forma de intelecção e do exercício dos prazeres foi essencial para a invenção dos Direitos Humanos e se tornou essencial para a sua conservação. Vivenciar estes Direitos criou uma maior estabilidade e confiança social, incentivando vários outros avanços junto à sociedade: científico, tecnológico e econômico.

As mudanças na forma de conhecer e compreender o mundo trouxeram novas necessidades, aumentaram, igualmente, os contatos sociais e o compartilhamento de experiências. 0 aprimoramento dos comportamentos e da sensibilidade humana trouxe consigo uma nova consciência da pessoa humana e a construção de um sujeito moral pleno em dignidade e sentido. 0 despertar desta consciência, a partir da compreensão do sofrimento e do compartilhamento dos infortúnios durante a vida, em especial, a morte e finitude humana, possibilitou a construção de uma "cultura de Direitos" na Civilização Ocidental. Nesse sentido:

\begin{abstract}
Acredito que a mudança social e política - nesse caso, os direitos humanos - ocorre porque muitos indivíduos tiveram experiências semelhantes, não porque todos habitassem o mesmo contexto social, mas porque, por meio de suas interações entre si e com suas leituras e visões, eles realmente criaram um novo contexto social. Em suma, estou insistindo que qualquer relato de mudança histórica deve no fim das contas explicar a alteração das mentes individuais. Para que os Direitos Humanos se tornassem autoevidentes, as pessoas comuns precisaram ter novas compreensões que nasceram de novos tipos de sentimento (HUNT, 2009, p. 33)
\end{abstract}

O homem, para se proteger da morte e dos infortúnios, consagrou a ideia de que, detendo direitos, a posse deles traria uma "ilusão de segurança" apta a tornar possível a paz social e uma convivência harmônica entre vários sujeitos. Não existe Direitos Humanos onde prevalece a brutalidade e a barbárie, porque estes direitos são produto de uma consciência humana que aperfeiçoa o dizer e o compreender o mundo, ou seja, a linguagem e a comunicação humanas. Violências não comunicam nada, apenas silenciam e intimidam o outro e sem consideração e respeito pela alteridade não existem direitos. Enfim, onde não há comunicação não existe Direito, mas poder da força, ou seja, exercício da violência. 
Há um canal que permite a consideração de "Universalidade dos Direitos Humanos": o sofrimento e a morte. Os Direitos Humanos são fruto da "sensibilização ao sofrimento do outro". Pelo outro, tomamos consciência da finitude da vida e sua narrativa de sofrimento é espelhada em nossa história pessoal. $\mathrm{O}$ acesso a instrumentos que nos protejam de tais sofrimentos, de nossos medos comuns, tornam-se hipóteses de interesse universal a partir de uma consciência cada vez mais apta, pela experiência sensível da existência, a produzir reconhecimento. Esta consciência também impõe limites sensíveis às nossas pretensões e as experiências intersubjetivas vão criando uma proposição acerca da eticidade necessária às relações humanas e o progresso em termos de respeito recíproco e compreensão dos limites produzidos pelos Direitos Humanos. Assim, esta consciência de si mesmo, ao encontrar resistência de determinadas pretensões, pode alcançar o nível da produção de reconhecimento:

\begin{abstract}
No novo contexto, o termo "reconhecimento" refere-se àquele passo cognitivo que uma consciência já constituída "idealmente" em totalidade efetua no momento em que ela "se reconhece como a si mesma em uma totalidade, em uma outra consciência, e há de ocorrer um conflito ou uma luta nessa experiência do reconhecer-se-no-outro, porque só através da violação recíproca de suas pretensões subjetivas os indivíduos podem adquirir um saber sobre se o outro também reconhece neles como uma totalidade (...) (HONNETH, 2003, p. 63)
\end{abstract}

A condição humana que sujeita todos aos mesmos riscos e o mesmo destino é, igualmente, a própria razão da universalidade, não uma razão fundada na utilidade e viciada pela simplificação controlada da linguagem como instrumento, mas uma razão fundada na existência e no sentido da vida para a morte, ou seja, na consciência comum de finitude e de necessidade de segurança quanto às condições da vida nesta caminhada para a morte. Por isso, a "emergência dos Direitos Humanos", eles devem ser fundamentados noutra razão, não aquela comum e instrumental da modernidade, mas numa razão de consciência da morte ou da finitude da vida, complexa e subjetivamente rica de personagens, ideias e formas de existir ou "sustentar o trabalho da morte" (MBEMBE, 2018, p. 12). Compreendendo que:

Em outras palavras, o ser humano verdadeiramente "torna-se sujeito" ou seja, separado do animal - na luta e no trabalho pelos quais ele ou ela enfrenta a morte (entendida como violência da negatividade). É por meio deste confronto com a morte que ele ou ela é lançado(a) no movimento incessante da história. Tornar-se sujeito, portanto, supõe sustentar o trabalho da morte. Sustentar o trabalho da morte é precisamente como 
Hegel define a vida do espírito. A vida do espírito, ele diz, não é aquela vida que tem medo da morte e se poupa da destruição, mas aquela que pressupõe a morte e vive com isso. 0 espírito só alcança sua verdade quando descobre em si o desmembramento absoluto. A política é, portanto, a morte que vive uma vida humana (MBEMBE, 2018, p. 12-13)

É esta consciência que promove uma razão existencial que se torna Universal e propicia a observância dos Direitos Humanos como instrumentos de "alívio" ao homem nesta "sustentação do trabalho da morte". A ausência destes Direitos produz o agravamento das condições da vida humana, resumindo a existência a uma condição meramente biológica, na qual este "trabalho da morte" não é sustentado de forma digna, sendo muitas vezes abreviado de forma seletiva. Portanto, os Estados que excepcionam o reconhecimento e gozo dos direitos humanos, abrindo espaço para a ausência da "vida do espírito", promovem uma assustadora história da maldade, porque retiram dos sujeitos a sua condição humana, o que os diferencia de uma vida meramente biológica e nua (AGAMBEN apud MBEMBE, 2018, p. 08).

\section{3 - Vida democrática e direitos humanos: os avanços num modelo social aberto}

O problema das perspectivas dicotômicas dos Direitos Humanos está nas respectivas pretensões hegemônicas, fundamentando-se numa "instituição imaginária de uma sociedade melhor" a partir de modelos ideais e abstratos. Até mesmo os instrumentos que se articulam para a produção desta "sociedade melhor" podem determinar exclusões, sofrimento e morte de pessoas e culturas comunitárias indesejadas no processo de transformação social. Este esforço de simplificação dos "cotidianos", próprio da razão instrumental moderna, cancelou várias alternativas e possibilidades de comunicação, bem como a ampliação da habilidade linguística de reconhecimento de sujeitos e direitos. É um esforço que promove o silêncio dos indesejados, sejam eles quem forem: judeus, ciganos, denominações religiosas, liberais ou socialistas. Quase sempre, tais intervenções de exclusão e morte são praticadas em Defesa da boa Sociedade, pois:

Em tais instâncias, o poder (e não necessariamente o poder estatal) continuamente se refere e apela à exceção, à emergência e a uma noção ficcional do inimigo. Ele também trabalha para produzir a mesma exceção, emergência e inimigo ficcional. Em outras palavras, a questão é: qual é, nesses sistemas, a relação entre política e morte que só pode funcionar no Estado de Emergência? (...) Esse controle pressupõe a distribuição da espécie humana em grupos, a subdivisão da população 
em subgrupos e o estabelecimento de uma cesura biológica entre uns e outros (MBEMBE, 2018, p. 17)

A questão é que, entre os vários grupos sociais, determinar o representante ideal desta sociedade melhor, conforme a ótica conservadora, liberal ou socialista, sugere, instrumentalmente, aplicar os meios empregados para a obtenção dos fins de "transformação" social, tornando incomunicáveis os sujeitos de outros mundos que se pretende alterar pelo silêncio ou pelo extermínio. Os Estados Autoritários, de matriz conservadora, liberal ou socialista, promoveram tais silenciamentos de grandes massas populares e humanas indesejadas. Criaram Estados de Exceção permanentes que, para além da separação dos grupos, igualmente fosse determinada a sua morte num território de exclusão e extermínio. Assim, aos guetos sucederam as periferias e aos campos de concentração, os territórios de exclusão. Criam-se colônias dentro das colônias.

Observando a crítica marxista aos Direitos Humanos, encontramos os mesmos traços desta "razão instrumental moderna" que subtrai a diversidade das experiências humanas nos argumentos que justificam a "implantação de uma sociedade socialista como forma avançada, científica e melhor de organização política". A crítica feita por Marx advém da percepção da forma original das Declarações de Direitos do Século XVIII dentro da ótica das revoluções liberais comprometidas com uma "leitura religiosa e metafísica da instituição política da sociedade" e a promoção instrumental e utilitária de um "sujeito individual" e proprietário. 0 entendimento de Marx é que estes direitos da primeira geração, em especial o reconhecimento da propriedade privada, expandiam a ideia do sujeito ou cidadão proprietário, limitando a liberdade e o reconhecimento do restante dos homens. Assim:

0 direito humano de propriedade privada é, portanto, o direito de arbitrariamente (à son grè \{à sua vontade - francês\}), sem referência a outros homens, independentemente da sociedade - gozar a sua fortuna e dispor dela; \{é\} o direito de interesse próprio (...). Aquela liberdade individual, assim como a aplicação dela, formam a base da sociedade civil. Ela faz com que cada homem encontre no outro homem, não a realização, mas antes a barreira da sua liberdade. Porém, ela proclama, antes de tudo, o direito do homem (MARX, 2009, p. 64)

De acordo com Marx, ainda que o avanço dos chamados "Direitos do Homem" produzissem espaço para a superação de "oposições religiosas" e para a demanda de emancipação política de determinadas categorias, como os judeus, na realidade tal superação seria sempre aparente e sujeita a retrocessos pelos 
mesmos princípios e formas instrumentais adotadas nestas Declarações de Direitos Individuais. Fortaleciam-se, por intermédio das Declarações de Direitos Liberais, as dimensões ideológicas e culturais necessárias a um sujeito proprietário, burguês ou pequeno burguês, não modificando a relação estrutural e econômica que impedia, a alguns, qualquer posse, inclusive da sua força do trabalho que acabava expropriada. Esta emancipação aparente encontrava os limites nas dimensões materiais da organização econômica da sociedade e que, por todo o tempo da existência dos sujeitos, permitia novas oposições conflitivas, colocando em risco a própria estabilidade ou gozo dos direitos adquiridos. Num reconhecimento de "direitos individuais", uma série de problemas são propostos pela crítica marxista a partir da própria ideia de como se processam o avanço e o reconhecimento dos direitos e da emancipação política:

O Estado Cristão conhece apenas privilégios. Nele, o judeu possui o privilégio de ser judeu. Como judeu, ele tem direitos que os cristãos não têm. Por que pretende ele direitos que não tem e de que os cristãos gozam? Quando o judeu quer ser emancipado do Estado cristão, deve exigir que o Estado cristão abdique do seu preconceito religioso. Abdica ele, o judeu, do seu preconceito religioso? Tem ele, portanto, o direito de exigir a outrem essa renúncia à religião? (....) A forma mais rígida da oposição entre o judeu e o cristão é a oposição religiosa. Como se resolve uma oposição? Pelo fato de a tornar impossível. Como se torna uma oposição religiosa impossível? Pelo fato de se suprimir \{aufheben\} a religião. Assim que judeu e cristão só reconhecerem as suas respectivas religiões como estágios de desenvolvimento diversos do espírito humano , como peles de cobra diversas que a história se despiu (e o homem como a cobra nelas larga a pele), eles deixam de estar numa relação religiosa, mas apenas numa \{relação\} crítica, científica, numa \{relação\} humana. A ciência é então a unidade deles. Oposições em ciência resolvem-se, porém, pela própria ciência (MARX, 2009, p. 40-41)

De fato, para a superação dos conflitos religiosos, melhor a observância de uma forma de Estado Laica que consiga abranger todas as religiões, tornando esta "oposição impossível" como bem dito por Marx. A questão que se propõe é observar a ciência e os fundamentos que operam a racionalidade científica como fim último da consciência humana e possibilitador de "existências livres". Desconfio que as experiências práticas e políticas do materialismo histórico nos deram conta de que a ciência também opera em seu sentido "um conjunto de maldades" e não auxilia, muitas vezes, este processo político de sustentação da morte e alívio do sofrimento humano que é profundamente existencial e subjetivo. Que Marx desconfiasse das fundamentações metafísicas das primeiras declarações e da oportunidade, com fundamento nelas, de se perseguirem pessoas e grupos 
sociais por interpretações casuais e convenientes do direito em favor de circuitos de individualidades hegemônicos não podemos desprezar como um alerta de risco comum. Todavia, a experiência histórica igualmente nos confirma como a ciência pode ser utilizada, de forma conveniente, para a perseguição de pessoas e grupos sociais, logo não é esta consciência científica o modelo final de razão do qual necessitamos para ampliar e diversificar os Direitos Humanos. A razão científica é um produto do método da modernidade, é ela própria a essência da razão instrumental, pretensamente, "emancipando o homem" e dotando-o de uma capacidade infinita de acúmulo de conhecimento e da articulação dele para determinados fins. A questão é que, em função da complexidade e da dinâmica da existência humana, o mecanismo meio e fim, estipulado pela razão instrumental e pela ciência, não funciona, adequadamente, diante da diversificação de interesses subjetivos e de projetos de vida.

As lições originadas em ambientes abertos e democráticos demonstram que há mais chances do processo comunicativo ser enriquecido e ampliar o reconhecimento de sujeitos e de direitos onde o papel do Estado não monopoliza as formas de vida e a existência social, direcionando-as num único sentido, por mais "científico" e correto que se pretenda o caminho a ser tomado. A experiência da Democracia, mesmo quando a participação observasse parâmetros desiguais entre sujeitos, tempos históricos e objetivos de grupos e pessoas diferentes, foi propiciadora de avanços nas várias perspectivas da atuação humana. Descrever esta experiência desordenada e por vezes irracional é revelar surpresas com relação as suas consequências:

O que mais impressiona ao chegar aos Estados Unidos é a espécie de movimento tumultuado no seio do qual está situada a sociedade política. As leis mudam sem cessar e à primeira vista parece impossível que um povo tão pouco seguro de sua vontade não vá logo substituir a forma atual de seu governo por uma inteiramente nova. Esses temores são prematuros. Há, em matéria de instituições políticas, duas espécies de instabilidade que não se deve confundir: uma tem a ver com as leis secundárias, e pode reinar por muito tempo no seio da sociedade bem assentada; a outra abala sem cessar as bases mesmas da constituição, ataca os princípios geradores das leis e é sempre seguida de turbulências e revoluções - a nação que a sofre acha-se num estado violento e transitório. A experiência demonstra que essas duas espécies de instabilidade legislativa não têm entre si vínculo necessário, pois já se viu existirem conjunta ou separadamente, segundo os tempos e os lugares. A primeira se encontra nos Estados Unidos, mas não a segunda. Os americanos mudam frequentemente as leis, mas o fundamento da constituição é respeitado (TOCQUEVILLE, 2005, p. 457-458) 
O aparelho burocrático racional socialista voltado a produzir igualdade, ao se isolar numa autorreferência ideológica, tornou-se reducionista das vidas humanas geridas e oportunizou vários questionamentos em favor da liberdade e contrários ao autoritarismo das formas de gestão política vigentes. A demanda da sociedade justa, igualitária e melhor, por este modelo, reproduziu atrocidades, cancelamento de sujeitos e linguagens de ódio e violência. No final, esgotou-se por tentar impor a ciência como modelo de expressão da vida social, alterando cotidianos e projetos de vida sem respeito à autonomia moral e individual dos sujeitos. Este corpo do povo é realmente formado por sujeitos individuais, não existe de outra maneira a não ser como abstração. Assim, Luciano Oliveira pronunciando as razões para o abandono do marxismo por Lefort pondera:

Lembremo-nos de que o conceito de povo remete a algo como uma unidade dotada de identidade, vontade - numa palavra, e mesmo correndo o risco de repetição, a uma "totalidade orgânica". Ora, tal entidade não existe empiricamente, mas apenas simbolicamente. 0 que existe empiricamente - e olhe lá! - são pessoas, grupos, classes, interesses, diferenças, modos de vida singulares etc. Nesse caso, a "loucura" do totalitarismo consistiria precisamente numa confusão entre "o simbólico e o real", e numa "irresistível tentação" de precipitar aquele neste. Evidentemente, à vista até de suas dificuldades empíricas, essa "precipitação" se daria por intermédio de uma "figura" que corporificaria o indefinível povo: a raça ariana, o proletariado etc. "Loucura" - eis como Lefort define esse projeto (...) Num texto já citado em que ele dá as razões por que abandonou o marxismo e a perspectiva revolucionária, essa preocupação em preservar o simbólico de uma realização que o aniquilaria já está presente. Aí Lefort refere-se ao "mito" cultivado pelos comunistas de uma "indivisão, de uma homogeneidade, de uma transparência da sociedade para si própria", a realizar-se na sociedade comunista futura, mito do qual "o totalitarismo mostrava os estragos pretendendo inscrevê-los na realidade" (2010, p. 84-85)

Os modelos políticos têm pretensões hegemônicas e quase sempre rompem, sem qualquer diálogo, com tradições, práticas comunitárias e vidas religiosas que se colocam como obstáculos indesejados em sua ânsia modernizadora ou de homogeneidade social. Criam, neste percurso, uma dissociação com a realidade social. Todos os instrumentos postos em favor da liberdade são, muitas vezes, observados como impeditivos ao sentido de transformação social almejado. Por outro lado, irão sempre existir insatisfações, insuficiências e busca por modelos alternativos, considerados mais seguros, em prol da consecução dos objetivos sociais instrumentalizados a partir dos valores apresentados pela "boa sociedade". O fato é que o desenvolvimento das habilidades comunicativas, a possibilidade de estabelecer relações horizontais mais densas e permanentes, observadas algumas 
ressalvas, são sempre mais vantajosas para o contínuo aprendizado social dos direitos e da "arte de convivência comum e diversa" de que o processo de centralização política estatal, sugerido pela modernidade, por intermédio dos seus vários modelos políticos e sociais centrados em "abstrações". A aparente desordem democrática alimenta um ambiente comunicativo adequado para o aprendizado e o reconhecimento de sujeitos e dos direitos humanos. Depois, há mais enriquecimento subjetivo e da linguagem num contexto em que a diversidade de opiniões e de expressão pessoal e do pensamento 'são respeitadas. Ainda que reconheça que, para a "sustentação do trabalho da morte," há o componente de integração em dimensões cada vez mais amplas de agrupamento dos indivíduos que o compõem, determinando um "imaginário sentimento coletivo de nós" (brasileiros, europeus etc...). Esta integração social e humana promove as condições de sobrevivência dos diversos grupos individuais (ELIAS, 1994, p. 181 190). E, mesmo diante de várias situações difíceis e de projetos políticos desumanos, ainda assim a desordem democrática propiciou, gradualmente, muitos avanços, como bem definido por Chomsky sobre a história de vitórias da "multidão inquieta" dos Estados Unidos:

O País é muito mais livre do que há duzentos anos. Em primeiro lugar, não temos escravos. Essa é uma grande mudança. 0 objetivo de Thomas Jefferson, na extremidade liberal do espectro, era criar um país "livre de mácula e mescla" - ou seja, nenhum indígena, nenhum negro, apenas bons anglo-saxões brancos. Isso era o que os liberais queriam. Não obtiveram sucesso. Conseguiram praticamente liquidar a população nativa - quase "exterminá-la", como disseram na época - mas não conseguiram se livrar da população negra. Com o tempo tiveram de incorporá-la de alguma forma à sociedade. A liberdade de expressão aumentou bastante. As mulheres finalmente receberam o direito de voto, 150 anos depois da revolução. Após uma luta sangrenta, os trabalhadores finalmente obtiveram alguns direitos, na década de 1930 cerca de cinquenta anos depois de fazê-lo na Europa (Eles têm perdido esses direitos desde então, mas, em certa medida, eles o conquistaram). Grande parte da população passou, de muitas maneiras, a fazer parte de um sistema de prosperidade e liberdade relativas, quase sempre em consequência de uma luta popular (1999, p. 123-124)

Todavia, nos vários contextos, é ainda possível certa "restauração de práticas comunitárias", mudando as formas e a velocidade de resposta das instituições democráticas. Uma democratização pela base, promovendo reaproximações entre sujeitos que, atualmente, têm as suas relações e ações exclusivamente mediadas pelo Estado. A interferência, em alguns momentos, não ocasiona apenas uma simplificação dos instrumentos de resolução de conflitos, 
mas produz um rápido empobrecimento da linguagem e das soluções para lidar com determinados conflitos. Todavia, práticas sociais, muitas vezes exitosas, preexistem à delimitação conceitual que as exprime como relação legítima ou reconhecida pelo papel integrador do Estado de Direito. Se, por um lado, o Estado pode se converter num grande "guardião de Direitos", ou seja, dos instrumentos que nos protegem contra o sofrimento humano, assegurando a nossa sobrevivência, por outro lado, a linguagem e as práticas sociais avançam e permitem novos reconhecimentos sem depender tanto da atuação do Estado neste sentido. Embora, obviamente, após o avanço marcado horizontalmente pelas relações intersubjetivas, precisamos do reconhecimento do Estado e da oferta de seus instrumentos de proteção. Trata-se de um processo contínuo de interdependência e aprendizado.

Daí os motivos para se desconfiar, por exemplo, da produção da igualdade numa "Ditatura do Proletariado", ou seja, num ambiente comunicacional controlado por uma ideologia de ordem exclusiva marxista. Sempre existirá um déficit de representação ou delimitação conceitual a ser suprido a partir do acompanhamento da dinâmica social. Enfim, o trabalho originado na comunicação humana nunca estará completo, exigindo uma contínua restauração dos relacionamentos e da linguagem a fim de avançarmos em termos do reconhecimento de novos sujeitos e de direitos. Fixar, em princípio, modelos a serem planejados e produzidos pelo aparelho burocrático racional do Estado traz muitos riscos, entre eles, o de já não atender mais ao que é pretendido pela dinâmica social como conteúdos de liberdade, igualdade ou fraternidade. Precisamos compreender que há uma permanente mutação em curso pelo desenvolvimento da linguagem ou diversificação das aspirações sociais e comunitárias, o que não significa empobrecimento, mas possibilidades de alterar sentidos e alcançar novos reconhecimentos. As vezes, existe nesta comunicação a "restauração de formas" que estipulávamos ultrapassadas ou, em outros momentos, a comunicação ultrapassa as formas comuns, atualmente vigentes e permite uma restauração do sentido de Direitos Humanos e todos os demais princípios correlacionados pela própria sociedade. A produção dos avanços democráticos é lenta, mas tende a ser durável e satisfatória para um conjunto maior de pessoas. 
A questão que se põe agora é quando esta linguagem aberta e democrática traz riscos de retrocessos? Aqui, de fato, retornarmos ao papel do Estado de guardião daquilo que foi conquistado e não temos muitas escolhas neste sentido. A democracia não pode ser tão aberta ao ponto de que nela se possa optar pelo seu fim. A consciência comum do sofrimento humano e dos perigos que determinam tais violências e atrocidades traz a necessidade de uma atuação guardiã do Estado e de seus atores políticos. Não podemos retroceder em Direitos, daí a motivação para o desenvolvimento do próximo tópico deste artigo.

\section{4 - A conservação de Direitos Humanos como paradoxo democrático: a ideia de Constituição}

Se os Direitos Humanos consagram instrumentos de proteção contra o sofrimento humano comum, logicamente temos que encontrar formas de conservá-los. É preciso relembrar as possibilidades de maiorias tirânicas, o que aparenta uma contradição com o último tópico desenvolvido. Até o momento, exaltamos as qualidades de um modelo aberto e democrático para a vivência e o florescimento dos Direitos Humanos. Agora, compreendemos que há decisões políticas que, embora tenham uma produção democrática, legitimação de maioria, são violadoras desses direitos. A preservação dos Direitos Humanos é, diante deste cenário, uma efetiva atitude conservadora em relação ao que foi arduamente conquistado. Ou seja, uma consciência do paradoxo que envolve Direitos Humanos e Democracia é saber que, nem sempre, as decisões de maioria representam efetivação e/ou conservação dos Direitos Humanos. Por isso, a contrariedade e resistência às pretensões majoritárias violadoras de Direitos Humanos precisa de uma mediação política e normativa. Conciliar a ordem pública e a liberdade individual é , como mostrava Kant, tarefa do Direito Político Moderno (GOYARDFABRE, 2002, p. 354). Há quem veja, na "inflação das liberdades democráticas," um grave risco ao Estado de Direito e à segurança dos sujeitos sociais que o compõe. Observe, desta forma, os seguintes argumentos:

Hegel tinha razão em dizer que a liberdade individual "leva em sua fronte o ódio pela lei" (...) Hoje, no direito político, triunfa o relativismo. A lei já não está, segundo o desejo de Rousseau, "acima dos homens". No horizonte, nas brumas de uma fragmentação pluralista que alguns pretendem "cultural", vemos adiantar-se e crescer, ameaçadora, a "crise" do direito político moderno. A questão será saber se esta crise será superada (GOYARD-FABRE, 2002, p. 355). 
Esta perspectiva tomada de forma absoluta não nos interessa, porque confiamos na democracia como agente de mudanças. Apenas nos certificamos de qual parte das leis e costumes pode ser submetida à instabilidade democrática como alertado acima na última referência feita da obra de TOCQUEVILLE (2005). A democracia se baseia numa força das maiorias, já os Direitos Humanos compreendem estatutos que vislumbram o sofrimento de sujeitos, numa luta existencial por sobrevivência e reconhecimento da identidade que somente cada um pode expressar. Noutras palavras, há nos Direitos Humanos uma razão existencial que não é a mesma razão instrumental observada em modelos políticos que determinam as formas de governo do Estado Moderno. Entretanto, a própria ideia de Direitos Humanos acaba consagrando uma forma de resistência contramajoritária: a Constituição. Esta norma torna-se um instrumento para defesa das minorias e resiste a mudanças bruscas do cenário social que ocasionem situações de exclusão e sofrimento humano impensáveis. Por isso:

\footnotetext{
O constitucionalismo assegura que a mudança constitucional será lenta, em comparação com a via rápida da política parlamentar normal. $\mathrm{Na}$ maioria dos países, a necessidade de uma maioria qualificada para uma emenda constitucional, com a raridade de grandes maiorias no Parlamento assegurará que as constituições de fato mudem raramente. Em países com uma tradição constitucional mais antiga, poderosas convenções não escritas podem também impedir os políticos de emendar constantemente a Constituição para promover fins partidários ou de curto prazo (ELSTER, 2009, p. 133)
}

A ideia de Constituição e exercício de força contramajoritária intui que os mecanismos democráticos possibilitam manifestações que, em alguns aspectos, agridem os Direitos Humanos, daí oportunizam a formação de consensos e de maiorias históricas que contrariam fundamentos e princípios inerentes aos Direitos Humanos (GOYARD-FABRE, 2002, p. 346). Multidões muitas vezes cedem aos apelos autoritários e assim como se juntam, em meio às emoções de um momento, e assumem uma postura favorável ao linchamento de pessoas desviantes nas ruas, igualmente podem estipular e favorecer modelos políticos autoritários ou inspirados em ideias e manifestações autoritárias. Aqui é preciso compreender o movimento de conservação dos Direitos Humanos: a reação contramajoritária exigida da parte das funções do Estado e de sujeitos e atores políticos nacionais e internacionais no impedimento de quaisquer retrocessos em termos de direitos políticos ou sociais. A democracia pode levar a formação de 
opiniões e deliberações de massas ou mesmo funções e atores políticos que contrariam os Direitos Humanos. Nestes casos, os Direitos Humanos correm riscos que somente podem ser contornados se o Estado Democrático de Direito desenvolver mecanismos de conservação de valores e de preservação dos instrumentos que asseguram aos sujeitos o gozo de tais direitos. Primordialmente, este é o papel do controle de constitucionalidade exercido nas Côrtes Constitucionais.

A invenção da Constituição e da possibilidade do controle de constitucionalidade e da resistência às modificações bruscas e não fundadas na razão existencial, determina uma função importante ao Estado: conservar os valores fixados pelos Direitos Humanos é conservar as condições de vida digna dos sujeitos destes direitos. Podem-se imaginar, neste cenário de conservação, possibilidades de um "retrocesso do ambiente democrático", o surgimento de linguagens violentas e vindicativas que nem sempre equacionam os problemas individuais e sociais postos naquele conflito. Neste sentido, coordenar o ambiente comunicacional, a fim de que ele não perca as categorias que o permitam continuar democrático e aberto é exatamente definir as possibilidades de resistir aos recuos de linguagem que fundamentem silenciamentos e cancelamentos do outro. Estas maiorias precisam da reação contramajoritária representada pelos Direitos Humanos. Afinal, apesar de serem direitos da maioria, inerentes a todos e produto dos avanços democráticos, são, sobretudo, os direitos que permitem às minorias se expressarem socialmente. A proteção contra o sofrimento humano e a "sustentação do caminhar para a morte" em condições dignas e respeitosas constituem "limites da razão" que não podem ser submetidos ao escrutínio de maiorias históricas ocasionais. Aqui, de fato e grifo nosso, os direitos humanos evidenciam a norma sem a qual a política seria impensável (GOYARD - FABRE, 2002, p. 305).

As democracias possuem uma perspectiva dupla: manifestação das maiorias e oferta de canais de expressão e proteção às minorias. É preciso lembrar que nem toda minoria é tão reduzida em termos populacionais, há minorias que são verdadeiras maiorias (CHOMSKY, 1999). O problema é o déficit de representação ainda não totalmente resolvido nas democracias modernas. Portanto, independente destes conceitos, a questão que se põe é a de que esta legitimação da maioria é sempre provisória e limitada no tempo, bem como de que há certas 
mudanças que nem mesmo uma maioria pode fazer, sob pena de, igualmente, colocar-se em risco. Por estes fatos, os Direitos Humanos se tornaram um instrumento válido para defender todos contra maiorias tirânicas. Um governo que se fundamenta,, exclusivamente, no papel das maiorias, sem observar o fundamento de razão existencial presente nos Direitos Humanos perde o próprio sentido da democracia e da política que não é apenas um regime de decisão por maiorias, mas um regime de expressão geral, onde mesmo os derrotados nas urnas e as minorias podem se expressar e conviver, harmonicamente, com os demais.

Para além do controle de constitucionalidade, a Declaração Universal dos Direitos do Homem da ONU e outros Tratados e Convenções Internacionais de Direitos Humanos criam igualmente limites a serem cobrados aos Estados signatários. Aparentam uma agressão à soberania e à democracia destes Estados, mas legitimam posições que foram aprovadas e ratificadas pelos próprios Estados em seu exercício da soberania. Logo, não contrariam princípios políticos ou a autonomia dos próprios Estados signatários, uma vez que eles assinam e se submetem aos tratados exatamente por sua autodeterminação. E assim como no ordenamento jurídico interno, onde as decisões, por maioria histórica, tomadas por uma geração acabam influenciando as demais ou mesmo as vinculando, isso ocorre a partir destas normas: as instituições internacionais buscam nos Estados fortalecer os dispositivos e instrumentos que efetivam os Direitos Humanos.

Não há qualquer "perda democrática" ao se contrariar uma maioria em favor das normas que fixam limites contra abusos do Estado e proteção contra qualquer sofrimento humano. As maiorias existem pela junção de diversas minorias, ou seja, são elas próprias protegidas a partir deste ângulo sem que haja qualquer contrariedade a um princípio político que fundamente o funcionamento do Estado Democrático de Direito. Neste sentido, muitas vezes, somente protegemos ou conservamos os Direitos Humanos, contrariando maiorias históricas ocasionais. É bom lembrar, igualmente, que todas as maiorias são históricas, fixadas no tempo, não existem maiorias permanentes. Os regimes que pretendiam maiorias permanentes criaram Estados de Exceção Permanentes, ou seja, suspenderam direitos ou limitaram a liberdade de uma ampla parcela dos seus cidadãos. A experiência socialista da Rússia e do Leste Europeu quanto a uma pretensa maioria permanente proletária e as experiências nazista ou fascista de 
maiorias nacionais e de classes superiores, revelaram que é, exatamente, contra maiorias políticas transitórias que conservamos os Direitos Humanos. Este é o paradoxo: a democracia é que permite o florescimento e a ampliação do reconhecimento de sujeitos e de direitos, mas são igualmente as maiorias históricas e ocasionais que mais podem atentar contra os Direitos Humanos. Daí, ser necessário valer-se de formas e de mecanismos que protejam os Direitos Humanos da "tirania das maiorias" e preservem, sobretudo, os indivíduos e grupos sociais indesejados por estas maiorias transitórias de investidas autoritárias e violentas.

\section{5 - Considerações finais}

O sofrimento humano e medidas de contenção ou eliminação dele são os fundamentos para o estabelecimento dos Direitos Humanos. É impossível uma existência sem sofrimento, mas as dores correspondentes a ele são elementos de sensibilização do outro. Espelhamento capaz de encontrar a correspondência moral que reconhece sujeitos e direitos atenta para uma busca de proteção comum contra os males que ocasionam sofrimento. Como esta experiência do sofrimento é universal, tais instrumentos e direitos podem ser reclamados universalmente pela comunhão de existências, sujeitas ao mesmo destino e aos mesmos sofrimentos.

Os Direitos Humanos não são apenas mecanismos de pacificação comum da sociedade, mas a própria razão existencial que acompanha o homem. Estabelecem os limites da consciência humana e o seu dever de respeito à alteridade como condição de conservação e existência. Podem não ser instrumentos de transformação e modificação da sociedade, mas são o resultado de um desenvolvimento da linguagem e das habilidades de comunicação que permitem proteger os valores da existência humana diante de práticas e exercícios políticos que rompem, instrumentalmente, com esta forma complexa da razão. Em determinados momentos, os Direitos Humanos chegam mesmo a denunciar a "necropolítica" ou a "eugenia social e orgânica," pretendida pelos modelos que buscam a instalação da "boa sociedade" ou daquilo que concebem como uma "sociedade científica e desenvolvida". 
Certamente, os que buscam uma sociedade melhor possuem sua concepção de Direitos Humanos e colocam-na com um objetivismo valorativo que perturba a própria noção de valor existencial e subjetivo, estabelecido por parte dos Direitos Humanos. Trata-se de visões hegemônicas que, em sua produção instrumental, esquecem a diversificação das percepções subjetivas e locais do exercício destes valores da existência. 0 que importa é que, na busca de produção de consensos, não se simplifique tanto as relações e se perca a riqueza de linguagem e comunicação, representada por diferentes formas de existência individuais e a produção decorrente do cotidiano. Em todas estas formas, podemos perceber uma preocupação comum com a minimização do sofrimento humano, o reconhecimento da identidade e o respeito pela alteridade. Algumas, inclusive, com propostas que avançam diante da proposição comum e instrumental dos Direitos Humanos. Daí a necessidade de ampliar os ambientes comunicativos e democratizar os canais de expressão das várias experiências, consagrando formas plurais de serem vivenciados os Direitos Humanos.

Ainda assim, existe sempre o risco de este "caminhar democrático" sofrer ataques provenientes de maiorias históricas ocasionais. Neste ponto, é inevitável a articulação de uma utilização instrumental e de resistência ao retrocesso por parte dos Direitos Humanos. A conservação de direitos exige uma articulação a partir dos poderes organizados, recordando que toda maioria é provisória e que quaisquer consensos formados por maiorias não podem colocar em risco a razão existencial que funda a humanidade. Afinal, maiorias históricas se, por um lado, são um importante sinal da vida democrática e da alternância política, por outro, devem encontrar limites nesta razão existencial. Para alguns, esta perspectiva contrarrevolucionária dos Direitos Humanos representa a "manutenção de privilégios" e de "favorecimentos" a determinadas categorias de pessoas. 0 fato é que os valores de existência e a busca de proteção contra o sofrimento não são privilégios, mas a própria essência da dignidade da pessoa humana, daí não podermos abdicar jamais destes bens sobre pena de colocarmos um fim na própria ideia democrática de sociedade. A sociedade não é democrática apenas em função de decidir por maiorias, mas pela possibilidade de expressão e representação política das minorias, a garantia de sua existência e de articular politicamente demandas junto aos órgãos políticos. Desta forma, as maiorias ocasionais e 
históricas também encontram limites para a sua atuação política dentro de uma sociedade democrática e os Direitos Humanos se transformam em tais limites.

A invenção dos Direitos Humanos traz consigo, igualmente, um dever de conservação e vedação de retrocessos, porque são estes direitos que desenvolvem, moralmente, o homem e permitem uma consciência de si e do outro que não permite mais uma trajetória de maldades. É preciso desenvolver uma eticidade complexa e menos simplificadora das relações humanas, compreendendo que a história nos trouxe até aqui, nos deu consciência dos conflitos que circundam a existência humana e não nos permite retrocessos quanto à dignidade da pessoa humana, ou seja, no tocante às medidas de proteção contra o sofrimento humano e sustentação digna da vida em sua caminhada para a morte. Conservamos os Direitos Humanos a fim de que possamos avançar em várias outras questões e emergências. A maior emergência de um Estado Democrático de Direito é a proteção e defesa dos Direitos Humanos.

\section{Referências:}

CHOMSKY, Noam. A Minoria Próspera e a Multidão Inquieta. Trad. Mary Grace Fighiera Perpétuo. 2ª ed. Brasília: Editora Universidade de Brasília, 1999.

ELIAS, Norbert. A Sociedade dos Indivíduos. Trad. Vera Ribeiro. Rio de Janeiro: Jorge Zahar Editor, 1994.

ELSTER, Jon. Ulisses Liberto: estudos sobre racionalidade, pré-compromisso e restrições. Trad. Cláudia Sant'Ana Martins. Campinas: Editora UNESP, 2009.

GOYARD-FABRE, Simone. Os Princípios Filosóficos do Direito Político Moderno. Trad. Irene A. Paternot. São Paulo: Martins Fontes, 1999 (2002).

HONNETH, Axel. Luta por Reconhecimento: a gramática moral dos conflitos sociais. Trad. Luís Repa. São Paulo: Ed. 34, 2003.

HUNT, Lyn. A Invenção dos Direitos Humanos: uma história. São Paulo: Companhia das Letras, 2009.

MARX, Karl. Para a Questão Judaica. Trad. José Barata-Moura. São Paulo: Editora Expressão Popular, 2009.

MBEMBE, Achille. Necropolítica: biopoder, soberania, Estado de Exceção, Política da Morte. Trad. Renata Santini. São Paulo: N-1 Edições, 2018.

OLIVEIRA, Luciano. O Enigma da Democracia: o pensamento de Claude Lefort. Piracicaba: Jacintha Editores, 2010.

SKINNER, Quentin. As Fundações do Pensamento Político Moderno. Trad. Renato Janine Ribeiro e Laura Teixeira Motta. São Paulo: Companhia das Letras, 1996.

TOCQUEVILlE, Alexis de. A Democracia na América: livro 1 - Leis e Costumes. Trad. Eduardo Brandão. 2ª ed. São Paulo: Martins Fontes, 2005. 